\title{
LEITURA DA PAISAGEM COMO ESTRATÉGIA PARA PROTEÇÃO DO PATRIMÔNIO NATURAL:UMA EXPERIÊNCIA NA RPPN ESTÁDUAL MO'Ã EM ITAARA/RS
}

\author{
Leticia Ramires Corrêa $^{(\mathrm{a})}$, Tuane Telles Rodrigues ${ }^{(\mathrm{b})}{ }$ Cibele Steffano $^{(\mathrm{c})}$, Marina Deon Ferrarese ${ }^{(\mathrm{d})}$ \\ (a) Departamento de Geociencias/Curso de Pos-graduação em Geografia, Universidade Federal de Santa \\ Maria, leticiarcorrea@gmail.com \\ (b) Departamento de Geociencias/Curso de Pos-graduação em Geografia, Universidade Federal de Santa \\ Maria, , Tuanytel@hotmail.com \\ (b) Departamento de Geociencias/Curso de Pos-graduação em Geografia, Universidade Federal de Santa \\ Maria, ,cibele2012stefanno@gmail.com \\ (b) Departamento de Geociencias/Aluna Especial do curso de graduação em Geografia/ Universidade Federal de Santa \\ Maria, ,maurideon@hotmail.com
}

\section{Eixo: GEODIVERSIDADE,GEOARQUEOLOGIA E PATRIMÔNIO NATURAL}

\begin{abstract}
Resumo
O presente trabalho tem como objetivo propor uma estratégia de leitura da paisagem por meio de uma trilha interpretativa na RPPN Estadual MO’Ã, que localiza-se no município de Itaara/RS. Por meio desta proposta,pretende-se ressaltar a valorização e preservação do patrimônio natural presente na RPPN, por meio da Interpretação Ambiental. Para isso buscou-se utilizar o método de análise sistêmica, pois para haver Interpetação Aambiental tem-se que compreender todos os elementos e suas relações entre si, para traduzí-las ao visitante. Portanto, as saídas de campo,permitiram que se elegesse como eixo principal da interpretação a mata ciliar, justamente pela sua dinâmica peculiar, transformadorada paisagem em períodos de elevada pluviosidade. Foram elencados 6 pontos para uma trilha autoguiada de $1,5 \mathrm{Km}$ no entorno do rio que faz a divisa da RPPN Estadual MO'Ã com outra propriedade. $\mathrm{O}$ meio interpretativo escolhido foi o folder, a fim de atribuir autonomia ao visitante em escolher os pontos de seu interesse.
\end{abstract}

Palavras chave:Interpretação Ambiental. RPPN Estadual MO’Ã. Trilha interpretativa.

\section{Introdução}

Instituída em 15 de junho de 2015, a Reserva Particular do Patrimônio Natural Estadual MO’ã, tem por finalidade promover a proteção dos recursos ambientais e a conservação da diversidade biológica, de acordo com a Portaria $n^{\circ}$ 80, de 15 de junho de 2015 . Possui uma área de 21,0156 hectares, com biota, hidrografia e geologia relevantes, compõe o Corredor Ecológico da Quarta Colônia, instituído em 2014, e que tem como objetivo ligar UC que possibilitam entre elas o fluxo de genes e o movimento da biota (BRASIL, 2014).

A RPPN Estadual MO’Ã está localizada no município de Itaara/RS,situado no Rebordo da Serra Geral,apresentando um relevo ondulado, contendo vales íngremes devido ao entalhamento fluvial típico 
da Escarpa, morros do Rebordo e áreas planas do Planalto. As altitudes apresentam uma amplitude de aproximadamente $500 \mathrm{~m}$, proporcionando uma paisagem de exuberante beleza. Sendo conhecida como a cidade dos balneários, Itaara é composta por uma rica flora e fauna, características da transição do Bioma Mata Atlântica para o bioma Pampa. Pela favorável beleza cênica, a cidade éalvo de visitantes que procuram espaços de lazer, com natureza abundante, que está diretamente relacionada com as características climáticas do município de Itaara, as quais se assemelham às condições climáticas da "região serrana" do Rio Grande do Sul.

De acordo com a classificação de Köppen, o clima da região é do tipo subtropical úmido "Cfa", no qual a temperatura mínima do mês mais frio varia entre $-3^{\circ} \mathrm{C}$ e $10^{\circ} \mathrm{C}$; e no mês mais quente a temperatura média é de $22^{\circ} \mathrm{C}$, proporcionando uma sensação térmica agradável. Tal condição climática torna-se um atrativo para turistas, principalmente da porção central do estado e que residem em municípios próximos, os quais mantêm em Itaara sua segunda residência, preferencialmente nos períodos de verão e inverno (SEMA,2014).

A região da RPPN Estadual MO'Ã é drenada pelos canais que compõe a micro bacia Arroio Manuel Alves, que é um dos afluentes do Arroio Grande, integrante da bacia hidrográfica do rio Vacacaí-Mirim, da região hidrográfica do Guaíba. A dinâmica fluvial desta bacia hidrográfica é bem peculiar, por seus canais possuírem grande energia de transporte nas porções de maior inclinação da vertente, o que facilita a ocorrência de enxurradas em períodos chuvosos (KORMANNet al., 2009), tornando difícil o acesso à propriedade. "Estas condições são verificadas nas porções de montante do canal fluvial, onde as vertentes se apresentam mais encaixadas, situadas na parte norte da área de estudo". (KORMANNet al., 2010, p.28).

Em função disso justifica-se esta pesquisa pela presença de uma RPPN em Itaara, com inúmeras possibilidades de Interpretação. As Reservas Particulares do Patrimônio Natural estão classificadas dentro do Sistema Nacional de Unidades de Conservação-SNUC como de Uso sustentável sendo de domínio particular e admitindo a visitação pública, permitindo a pesquisa científica e a visitação turística, recreativa e educacional (BRASIL,2000). Porém, em nível estadual, a RPPN está na categoria de Unidades de Proteção Integral, em função disso é permitido o uso de forma educacional com objetivo de preservação a partir da construção de um conhecimento sobre a natureza.

As proeminentes potencialidades da RPPN MO'Ã já são exploradas do ponto de vista científico, abrindo espaço para pesquisas relacionadas à conservação do patrimônio natural da região central do Rio Grande do Sul, como o Projeto Saúde da Água em 2014/2015. Este projeto da Fundação MO’Ã foi patrocinado pelo programa Socioambiental da Petrobrás, prevendo, dentre outras estratégias de intervenção, a 
inserçãona comunidade escolar do município, oferecendo formações de professores, clubes de ecologia e despertando o interesse da população em conservar os recursos naturais do município.

Em janeiro de 2016 a RPPN MO'Ã recebeu a visita de estudantes de diversas universidades do Brasil. A visita fez parte do XXI Encontro Nacional de Estudantes de Geografia que aconteceu na UFSM.Na ocasião, a filosofia da Fundação MO'Ã pôde ser compartilhada e sua história difundida entre os participantes goianos, maranhenses, cariocas, mato-grossenses e gaúchos que puderam trocar experiências. Mas no ponto de vista Interpretativo, não há ações realizadas, como trilhas ou visitantes na RPPN. Em função disso,abrir o espaço da Reserva Particular do Patrimônio Natural Estadual MO’Ã para visitação e educação ambiental, faz-se relevante, para abranger este público residente em Itaara e os demais municípios ao redor.

A necessidade de um espaço natural para a comunidade escolar de Itaara/RS é outro elemento que justifica a importância da RPPN, pois as quatro escolas que estão em funcionamento, sendo uma de educação infantil, duas de Ensino Fundamental e uma de Ensino Médio, totalizam 857 alunos (IBGE,2015). Sendo assim a demanda de projetos envolvendo meio ambiente e educação ambiental são grandes. Porém estes projetos acabam ficando carentes de um espaço em que os alunos possam ter um contato direto com a natureza.

Para tanto, a presente pesquisa apresenta uma proposta de trilha interpretativa na RPPN MO'Ã em Itaara/RS, por meio da interpretação ambiental com uma perspectiva didática e pedagógica, visando mostrar "in loco" o ambiente e as informações relacionadas à conservação da biodiversidade e o uso sustentável do fragmento de mata atlântica.

A partir da interpretação ambiental em Unidades de Conservação é possível revelar a natureza ao visitante de maneira que haja uma construção de conhecimento e transformação de atitudes. A Interpretação Ambiental está baseada na maneira de perceber o mundo e no uso dos sentidos, onde se pode ouvir, ver e tocar a natureza e encontrar motivação para a observação do espaço, no qual o visitante está inserido e no enriquecimento das vivências pessoais, principalmente junto às escolas locais, através do contato com as paisagens naturais (PROJETO DOCES MATAS,2002).

Através desta proposta pretende-se também contribuir para a sustentabilidade do Patrimônio Natural e tornar a RPPN Estadual MO’Ã um destino de referência em educação ambiental, um espaço privilegiado para o desenvolvimento de ações de sensibilização e de formação destinados a diferentes públicos,além de oferecer suporte para desenvolvimento e execução de projetos de investigação científica. Desta forma cooperar com entidades que promovam estudos, como as escolas de Educação Infantil, Fundamental e Médio da região central do estado, e universidades com projetos de extensão e de pós-graduação 
desenvolvidos no seu âmbito disciplinar e interdisciplinar. Os resultados desta pesquisa poderão ser utilizados como subsídio para o programa de uso público do Plano de Manejo da RPPN.

\section{Interpretação Ambiental: a paisagem}

Há muitas definições sobre IA (Interpretação Ambiental) abordadas em diversas obras, porém, nos conceitos de Freeman Tilden que é considerado o grande pensador da IA, e é citado sempre que este tema entra em discussão, entende-se por IA a tradução da paisagem de forma clara e precisa, porém, de forma prazerosa.Para isso, TILDEN (1977, p.3) esclarece que "O trabalho de revelar algo da beleza e do fascínio, da inspiração e do significado espiritual que se escondem por trás do que o visitante pode perceber com seus sentidos se chama interpretação".

A IA se faz um relevante componente de ligação entre a natureza e o homem, favorecendo a construção de uma cultura de conservação do patrimônio natural, que parte do sentimento de pertencimento, onde o visitante percebe o quanto se é parte de um todo, deixando de lado uma visão há muito tempo construída, de que a natureza está a serviço da humanidade, para exploração de reservas de recursos naturais. A interpretação possui quatro características que fazem dela uma peça especial: é comunicação atrativa; oferece uma informação breve; é realizada na presença do objeto em questão; e seu objetivo é a revelação de um significado(YORKE EDWARDS, 2001apudSILVA, 2012).Interpretação ambiental se constitui de um relacionamento de verdadeira imersão na natureza, nos quais espera-se respostas sensoriais e afetivas intensas, a partir da observação da paisagem, sob diferentes formas pelos participantes das atividades ao ar livre, trazendo um aprendizado sobre as relações do ser humano e a Terra, despertando emoções e sentimentos (LIMA-GUIMARÃES, 2010).

O hábito da interpretação do que há no entorno leva-nos ao desenvolvimento de uma consciência ambiental que, em muitos casos, se encontra fragilizada, devido ao atual modelo de vida da cultura urbana moderna, se comparada com outras culturas - rurais, agrícolas, coletoras ou caçadoras (LIMAGUIMARÃES, 2010).

Sendo assim, interpretar a natureza é orientar o olhar do visitante, de forma que ele seja capaz de compreender aquela paisagem, com todas as suas partes e relações. O conceito de paisagem, fortemente utilizado na ciência geográfica, evoluiu ao passar dos anos cada autor descreve-a de uma forma, resultando em conceitos com focos diferentes. (FERREIRA; BRITTO, (2011).A paisagem aqui entendida consiste no conjunto de elementos naturais e artificiais que fisicamente caracterizam uma área. 
Assim, a interpretação ambiental faz com que os visitantes em geral entendam melhor a história da Terra para respeitar, valorizar e cuidar da natureza e da cultura relacionada à paisagem; deve ser suficientemente sugestiva para estimular o indivíduo a uma mudança de atitude ou a adoção de certa posição ou conduta (SOUZA, 2014). Os visitantes não devem sentir-se da mesma forma como se estivessem em uma aula formal de sala de aula. As formas de comunicação adotadas em um ambiente menos formal devem ser diferentes.

\section{Trilha Interpretativa}

Desde os tempos mais remotos o ser humano utiliza trilhas para deslocar-se e para transporte. Porém atualmente, dentre suas funções destaca-se a recreação, a fim de buscar em um caminho em meio à natureza, contemplação e descanso da rotina agitada dos grandes centros urbanos (PROJETO DOCES MATAS,2002).As trilhas na atualidade possuem um sentido mais educacional e tornam-se aliadas da sustentabilidade,com a prática da Interpretação Ambiental.

A trilha interpretativa se caracteriza por ser uma trilha de curta distância, permitindo que o visitante faça várias leituras de uma mesma realidade ambiental. Seu princípio parte do contato direto com a natureza, da sensibilização e da tradução das informações para o visitante, de forma atrativa e recreativa (SECRETARIA DO MEIO AMBIENTE,2008)

Em vista que o referente trabalho visa à construção de uma trilha interpretativa autoguiada com foco na comunidade escolar, a fim de construir uma percepção ambiental a partir da IA, as experiências através das trilhas interpretativas e vivências na Natureza se constituem de relacionamentos de verdadeira imersão, ou seja, busca transportar o aluno a um espaço em que além de contemplar a natureza possa aprender e respeitar o meio ambiente.

Seguindo o Manual de Introdução à Interpretação Ambiental, há três métodos de Interpretação de Trilhas: autoguiada com painéis; guiada com a presença de um interprete; autoguiada com roteiros. No Quadro 1 a seguir as potencialidades e limites das trilhas autoguiadas:

Quadro 1 - Potencialidades e limites de trilhas autoguiadas em relação ao manejo e a utilização

\begin{tabular}{|c|c|c|c|}
\hline \multicolumn{2}{|c|}{ Quanto à utilização da IA } & Quanto ao manejo \\
\hline Potencialidades & Limites & Potencialidades & Limites \\
\hline $\begin{array}{c}\text { Indicada para } \\
\text { aqueles pais que } \\
\text { querem } \\
\text { explicar a seus }\end{array}$ & $\begin{array}{c}\text { É mais difícil } \\
\text { incorporar técnicas de } \\
\text { comunicação } \\
\text { atrativas do que nas }\end{array}$ & $\begin{array}{c}\text { Permitem o acesso em } \\
\text { qualquer época do ano, } \\
\text { por } \\
\text { não dependerem de um }\end{array}$ & $\begin{array}{c}\text { Estão sempre expostas } \\
\text { ao vandalismo }\end{array}$ \\
\hline
\end{tabular}




\begin{tabular}{|c|c|c|c|}
\hline $\begin{array}{l}\text { XVII Simpósio Brasileiro } \\
\text { de Geografia Fisica Aplicada } \\
\text { I Congresso Nacional } \\
\text { de Geografia Física }\end{array}$ & \multicolumn{3}{|c|}{$\begin{array}{l}\text { OS DESAFIOS DA GEOGRAFIA FÍSICA NA FRONTEIRA DO CONHECIMENTO } \\
\text { Instituto de Geociências - Unicamp } \\
\text { Campinas - SP } \\
28 \text { de Junho à } 02 \text { de Julho de } 2017\end{array}$} \\
\hline $\begin{array}{l}\text { filhos, aspectos de } \\
\text { seus interesses } \\
\text { e de seu nível de } \\
\text { compreensão }\end{array}$ & trilhas guiadas. & $\begin{array}{l}\text { guia. Portanto, podem } \\
\text { atrair } \\
\text { um maior número de } \\
\text { pessoas. }\end{array}$ & \\
\hline $\begin{array}{l}\text { Permitem que o } \\
\text { visitante } \\
\text { estabeleça o seu } \\
\text { próprio ritmo para } \\
\text { percorrer a trilha, } \\
\text { o que não } \\
\text { acontece numa } \\
\text { trilha guiada. }\end{array}$ & $\begin{array}{c}\text { Deve ser dirigida a um } \\
\text { visitante "médio", já } \\
\text { que } \\
\text { não pode satisfazer às } \\
\text { demandas dos } \\
\text { diferentes } \\
\text { níveis de } \\
\text { conhecimento, dentro } \\
\text { de um mesmo } \\
\text { grupo. }\end{array}$ & $\begin{array}{l}\text { Servem de orientação, } \\
\text { para aquelas pessoas que } \\
\text { estejam perdidas. Para } \\
\text { isso a trilha deverá estar } \\
\text { muito bem sinalizada. }\end{array}$ & $\begin{array}{l}\text { O local pode ficar } \\
\text { congestionado, se } \\
\text { utilizado } \\
\text { para outros fins. }\end{array}$ \\
\hline $\begin{array}{l}\text { Pode ser uma } \\
\text { alternativa } \\
\text { interessante, para } \\
\text { aquelas pessoas } \\
\text { que não gostam de } \\
\text { "passeios" } \\
\text { em grupos. }\end{array}$ & $\begin{array}{c}\text { Diferentemente da } \\
\text { trilha guiada, a } \\
\text { comunicação } \\
\text { só acontece num } \\
\text { sentido (do roteiro ou } \\
\text { placa } \\
\text { para o visitante...). Não } \\
\text { é suscetível a } \\
\text { adaptações. Restringe- } \\
\text { se ao } \\
\text { estabelecido nos } \\
\text { roteiros. }\end{array}$ & $\begin{array}{c}\text { Podem direcionar o } \\
\text { público para uma área } \\
\text { que } \\
\text { aceita uso mais intensivo, } \\
\text { poupando outras áreas } \\
\text { mais frágeis. }\end{array}$ & $\begin{array}{l}\text { O custo de manutenção } \\
\text { pode ser alto. }\end{array}$ \\
\hline
\end{tabular}

\section{Metodologia}

Diante da complexidade de propor uma leitura da paisagem da RPPN Estadual MO'Ã através da IA, o que melhor atende as necessidades desta pesquisa é a abordagem sistêmica, onde distinguir um sistema na multiplicidade dos fenômenos da superfície é ato mental, cuja ação procura abstrair o referido sistema da realidade evolvente (CHRISTOFOLETTI, 1979), ou seja, busca estabelecer os elementos existentes e suas relações. Para isso utilizou-se das seguintes etapas:

Na primeira etapa buscou-se apresentar uma revisão bibliográfica a respeito do conceito de interpretação ambiental e sua correlação com as Unidades de Conservação, a partir de bibliografia de THOMAS et al. (2011), KORMANN et al. (2010) e FERRARESE (2016) as quais durante anos realizaram pesquisas na RPPN Estadual MO'Ã subsidiando sua instituição e contribuindo para esta pesquisa com a caracterização da área e TILDEN (1957) e o Manual de Introdução à Interpretação Ambiental do Projeto Doces Matas 
OS DESAFIOS DA GEOGRAFIA FÍSICA NA FRONTEIRA DO CONHECIMENTO

Instituto de Geociências - Unicamp

Campinas - SP

28 de Junho à 02 de Julho de 2017

(2002) e o material Manejo de Trilhas: um manual para gestores (2008) como base fundamental para compreender a IA, assim como as etapas para escolher o tema, os tópicos e os meios de interpretação. Na segunda etapa partiu-se para as saídas a campo e investigação in loco da RPPN Estadual MO'Ã. A partir disso, foi determinado o tema central de estudo da trilha que é "Mata Ciliar". Foram selecionados 6 pontos para interpretação ambiental a partir da metodologia dos Indicadores de Atratividade de Pontos Interpretativos (IAPI) "que objetiva agregar ao potencial interpretativo de cada sítio selecionado, um valor qualitativo para aumentar a atratividade do local" (MAGRO;FREIXÊDAS,1998). Primeiramente foram coletados 10 pontos com GPS (Global Positioning System, modelo GarmineTrex 30), e foram transferidos para o computador com o auxílio do programa TrakeMaker, e visualizados utilizando o programa Google Earth, os registros fotográficos foram realizados com câmera NIKON COOLPIX L330, 20.2 Megapixels e descritos. Na segunda fase organizou-se um quadro com indicadores de atratividade. $\mathrm{Na}$ terceira fase construiu-se uma Ficha de campo que foi preenchida indicando a presença ou ausência de cada indicador e a pontuação final, como pode-se observar no quadro 2

\begin{tabular}{|c|c|c|c|c|c|c|c|c|c|c|c|c|c|}
\hline $\mathrm{N}^{\circ}$ Tema & $\begin{array}{l}\text { Linha } \\
\mathrm{V}\end{array}$ & $\begin{array}{c}\text { Linha } \\
\text { H }\end{array}$ & & Posição & & Esc & ala/Distant & & $\mathrm{Ac}$ & & Rocha & Epifita & Pontuaçắo \\
\hline & $(1)$ & $(1)$ & Nivel(1) & Inferior(1) & Superior(2) & 1ㅇlang(2) & Médio(1) & Fundo(3) & Visual(3) & Som(2) & (2) & (2) & \\
\hline Arroio & & $\mathrm{x}$ & & & $\mathrm{x}$ & & $\mathrm{x}$ & $\mathrm{x}$ & $\mathrm{x}$ & $\mathrm{x}$ & $\mathrm{x}$ & & 16 \\
\hline RPPN MQ'Ã & & $x$ & $x$ & & & $x$ & & $x x$ & $x$ & $x$ & $x$ & & 17 \\
\hline $\begin{array}{l}\text { Exoticas ou } \\
\text { Nativas }\end{array}$ & $x$ & & $x x$ & $\mathrm{x}$ & & $x x$ & $\mathrm{x}$ & & & $x$ & & & 11 \\
\hline Vista para o Morro & & $x$ & & $\mathrm{x}$ & & & & $x$ & & & & & 5 \\
\hline Carqueja & $x$ & & $x$ & & & $x$ & & & & & & & 4 \\
\hline Basaltos & & $x$ & $\mathrm{x}$ & & & & $\mathrm{x}$ & & & & $\mathrm{x}$ & & 5 \\
\hline Sarandi & $x$ & $x$ & $x$ & & $x$ & $x$ & & & $x$ & $x$ & $x$ & & 14 \\
\hline Poço Lambari & & $x$ & $x$ & & $x$ & $x$ & & $x$ & $\mathrm{x}$ & $x$ & $x$ & & 16 \\
\hline Cafeeiro-do-mato & $x$ & & $x$ & & & $\mathrm{x}$ & & & & & & & 4 \\
\hline Fungo do ar puro & $x$ & & $x x$ & $x$ & & $x x$ & $x$ & & & $x$ & $x$ & & 13 \\
\hline
\end{tabular}

Quadro 2: Ficha de campo com indicadores de atratividade. Os números entre parênteses indicam o peso atribuído aos indicadores selecionados, podendo variar para cada trilha

Para esclarecer melhor quais pontos são mais relevantes para a IA construiu-se um gráfico de colunas onde os 6 pontos que se destacam foram selecionados. Observa-se a Figural com os pontos selecionados e os valores de atratividade.

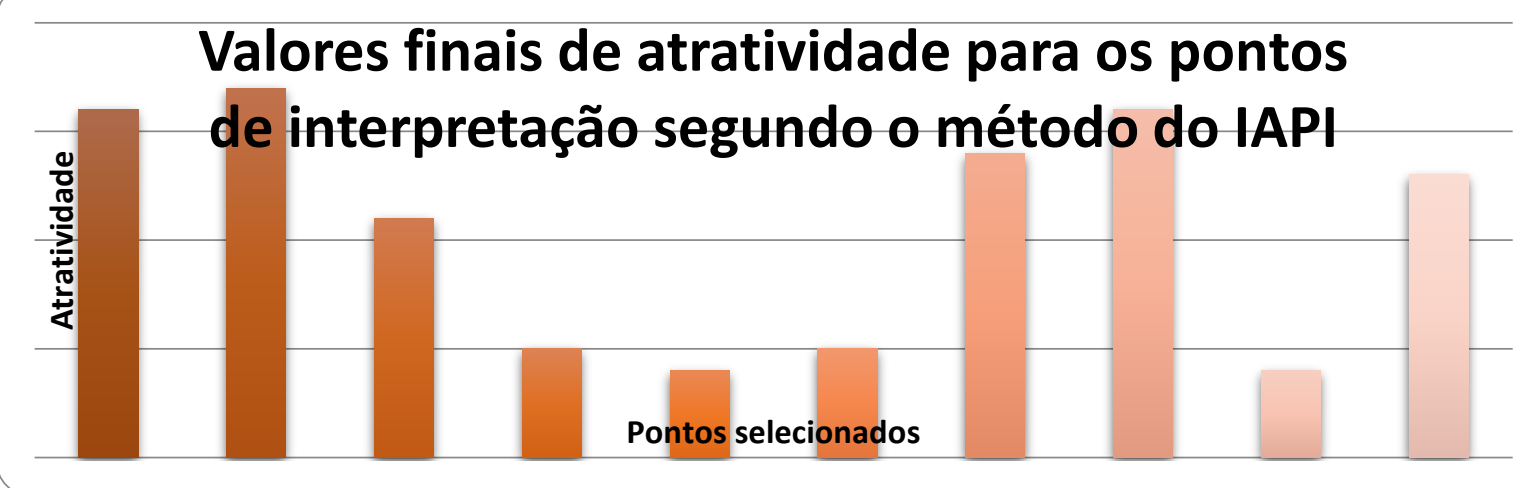


XVII Simpósio Brasileiro de Geografia Física Aplicada

I Congresso Nacional de Geografia Física
OS DESAFIOS DA GEOGRAFIA FÍSICA NA FRONTEIRA DO CONHECIMENTO

Instituto de Geociências - Unicamp

Campinas - SP

28 de Junho à 02 de Julho de 2017

Figura 1- Valores finais de atratividade para os pontos de interpretação Trilha do Arroio Manuel Alves.

\section{Resultados e discussões}

Ao considerar os estudos realizados por esta pesquisa, a RPPN Estadual MO’ Ã tem um potencial relevante para o município de Itaara, porém ainda pouco explorado no sentido da IA, muito em função da sua recente instituição. Portanto esta pesquisa propõe como estratégia de leitura da paisagem da RPPN Estadual MO’̃̃ através de uma trilha interpretativa autoguiada, pois segundo o Material Manejo de Trilhas: Manual para Gestores (2008), uma trilha de até $2.500 \mathrm{~m}$, é considerada uma trilha de curta distância e é destinada a atividades recreativas e educativas.

Após três saídas de campo foi decidido o tópico interpretativo que foi a Mata Ciliar, tal tema abre um leque para a IA, pois pode-se abordar o tema sobrea importância da mata ciliar para a conservação dos recursos hídricos. Na figura 2 observa-se o mapa de Localização da trilha do Arroio Manuel Alves.

Figura 1 Valores finais de atratividade para os pontos de interpretação Trilha do Arroio Manuel Alves.

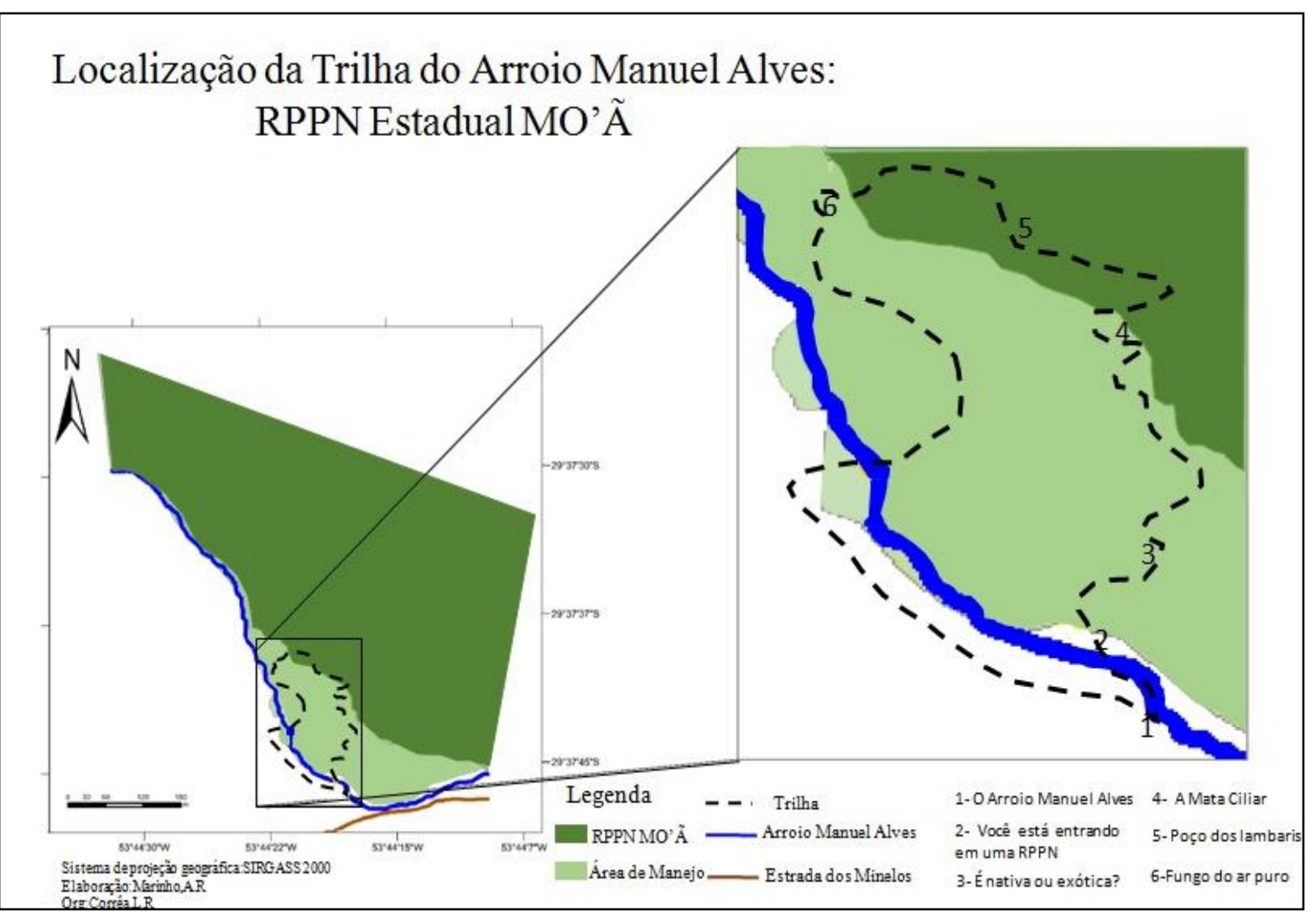


Figura 2 - Mapa de Localização da Trilha do Arroio Manuel Alves

Foram elencados 6 pontos para uma trilha autoguiada de 1,5Km no entorno do rio que faz divisa da RPPN Estadual MO’Ã com outra propriedade. Em relação ao grau de dificuldade é considerada uma Trilha Moderada, pois seu percurso é inferior a $1.500 \mathrm{~m}$, exigindo esforço físico moderado, apresentando pequenos obstáculos, como desníveis, escadas, pedras, troncos, riachos, mas não exigindo técnica específica. Em seguida os pontos selecionados e suas respectivas interpretações:

Ponto 1: O Arroio Manuel Alves(29³7'46.36"S / 5344'18.13"O)

No ponto 1 busca-se aguçar os sentidos do visitante, com o som e o tato, pois para acessar a RPPN Estadual MO'Ã necessita-se atravessar o rio, neste ponto o visitante é posto a sentir as rochas, basaltos do fundo do rio e o seu forte fluxo, podendo observar os matacões nas margens do rio, este que modifica a paisagem em cada enxurrada, portanto sensibilizar-se para a importância da conservação do patrimônio hídrico através da proteção da Mata Ciliar,e o respeito para com a força da natureza. O poder de transporte do rio, produz uma seleção granulométrica, desde os maiores blocos nas áreas de maior energia, até a deposição das areias mais finas e argila nos pontos de menor energia. Outra coisa se refere ao intemperismo físico representado pelos seixos rolados, de forma arredondada. $\mathrm{Na}$ área existem vários canais de rede de drenagem que compõem a subbacia hidrográfica do Arroio Manoel Alves, responsável pelo abastecimento domiciliar da população rural local e flutuante, população esta, que vem para Itaara nos períodos de verão em busca de lazer nos balneários da região, principal atração turística do município. O Arroio Manoel Alves é um dos afluentes do Arroio Grande, integrante da bacia hidrográfica do rio Vacacaí-Mirim, da região hidrográfica do Guaíba. Este rio tem características bem peculiares pela sua energia e capacidade de carga.A dinâmica fluvial desta bacia hidrográfica é caracterizada por canais de grande energia de transporte nas porções de maior inclinação da vertente, o que facilita a ocorrência de enxurradas em períodos chuvosos.

A RPPN Estadual MO’Ã está situada na margem esquerda da Bacia Hidrográfica do Arroio Manoel Alves. Na porção sul da propriedade,onde está incluída a trilha, encontram-se as menores cotas altimétricas, bem como as menores declividades isso reflete em uma perda de energia do rio em direção à jusante, a qual se pode afirmar que resulta em uma dinâmica de formação de ilhotas por deposição de blocos e matacões no leito do canal. Neste ponto pode-se ressaltar a importância da Mata Ciliar para o rio, em relação à manutenção da qualidade da água, a mata reduz o assoreamento e a força das águas que chegam aos rios, o que mantém sua qualidade ao impedir a entrada de poluentes para o meio aquático. $\mathrm{O}$ Arroio Manoel Alves em época de chuva intensa(cerca de 336 mm, em novembro de 2013), mostrou-se com grande vazão (KORMANN,2010). Em 2014 em função do fenômeno climático El niño houve uma 
maior concentração de chuvas,impedindo a entrada na RPPN Estadual MO’Ã, em função da ausência de uma ponte, pois a que foi construída pela Prefeitura Municipal de Itaara foi levada pelo rio (FERRARESE, 2016). Em 2015 moradores do entorno da propriedade ficaram ilhados em função do rompimento da ponte que passa por cima do rio que deságua no Arroio Manuel Alves Neste ponto pode-se esclarecer os fatores que influenciam na dinâmica fluvial, como a pluviosidade, que consiste na quantidade de água que este rio recebe em dias de chuva. Para o Arroio Manuel Alves é determinante a quantidade de chuva. Outros fatores como infiltração, evapotranspiração também são importantes, para determinar a dinâmica do rio.

Ponto 2: Você está entrando em uma Reserva Particular do Patrimônio Natural $\operatorname{RPPN}\left(29^{\circ} 37^{\prime} 46.44^{\prime \prime} \mathrm{S} / 53^{\circ} 44^{\prime} 17.95^{\prime \prime} \mathrm{O}\right)$

Neste ponto a informação não se refere a mata em si, mas sim às características da UC. Tem como objetivo explicar ao visitante o que são RPPNs, como são criadas, suas funções e importância, que são criadas por iniciativa dos proprietários, para conservar a natureza, ou seja, Reserva Particular do Patrimônio Natural (RPPN) é uma categoria de unidade de conservação criada pela vontade do proprietário, sem desapropriação de terra. No momento que decide criar uma RPPN, o proprietário assume compromisso com a conservação da natureza com perpetuidade, ou seja, mesmo que o proprietário venda sua terra a RPPN se mantém.Atividades recreativas, turísticas, de educação e pesquisa são permitidas na reserva, desde que sejam autorizadas pelo órgão ambiental responsável pelo seu reconhecimento (SNUC,2000). A RPPN Estadual MO’Ã possui 21,02 há e foi instituída em 15 de junho de 2015, e tem por finalidade promover a proteção dos recursos ambientais e a conservação da diversidade biológica. Esta área foi doada pelo casal Rainer e Eleonora à Fundação MO'Ã Estudos e pesquisas para a Proteção e o Desenvolvimento Ambiental.A palavra MO’̃̃ significa proteger em tupi-guarani. Apesar de não estar inserida no tema específico da interpretação considerou-se que seria importante o esclarecimento ao visitante de que a área se trata de uma unidade de conservação e as características principais dessa categoria, já que a proposta é de uma trilha autoguiada. Nesta área foram realizadas pesquisas relacionadas a Variáveis Climáticas, Solos e Levantamento Florístico, assim como visita de alunos da UFSM (SEMA,2014), destacando a importância desta UC para a pesquisa e Educação Ambiental, de forma que valorize a conservação da biodiversidade da área e promova a criação de novas UCs na região central do RS.

Ponto 3:É nativa ou exótica? (29³7'44.41"S/ 5344'18.25"O)

Neste ponto o visitante deve ser esclarecido inicialmente sobre as espécies nativas presente na Mata ciliar, que são aquela vegetação de uma determinada região que, durante milhares de anos, vêm interagindo com 
o ambiente e, assim, passou por um processo de seleção natural gerando espécies geneticamente resistentes e adaptadas ao local onde ocorrem. E sobre as espécies exóticas que são aquelas introduzidas de outras regiões, como de outro país, por exemplo, as quais não sofreram esse processo de seleção natural e, dessa forma, não servem de substituto ideal para a flora nativa, uma vez que não desempenham as mesmas funções dentro do ecossistema(CAMPOS et al.,2006). A partir disso o visitante, já adentrando a mata ciliar, tem contato com uma variedade nativa do bioma da Mata Atlântica.A gimnosperma nativa Araucaria angustifólia, conhecida como Araucária é nativa do Rio Grande do Sul, na floresta ombrófila mista e dominante nas partes elevadas do Planalto,podendo ocorrer na Serra do Sudeste (FLORA DIGITAL,2009). No ponto 2 o objetivo é esclarecer sobre a importância de Unidades de Conservação como a RPPN Estadual MO'Ã para a proteção de espécie sem risco elevado de extinção como é o caso da Araucária.Nesta RPPN foram encontradas 277 taxa nativos do Brasil (FERRARESE,2016). E também para compreender o que são espécies nativas e os danos causados pela espécie exótica invasora em áreas naturais, como por exemplo a Uva do Japão (Hovenia dulcisThunb.)originária da China, Japão e Coréia, atualmente éencontrada também no Brasil, Argentina, Paraguai,Uruguai, Estados Unidos, Cuba, Sul da Europa e Norte da África. Estes tipos de plantas, produzem descendentes em número muito elevado,que conseguem se dispersar a grandes distâncias da planta mãe, competindo com as espécies nativas.A dispersão de H. dulcis ocorre por seus frutos,carnosos ao madurar, com sabor doce e agradável. Em função disso as aves preferem seus frutos e não os das nativas. Diminuindo a disseminação das espécies nativas, (MAIEVES et al., 2015).

Ponto 4:Mata Ciliar e o Sarandi (29³7'41.24"S/ 5344'18.96"O)

Neste ponto o objetivo é compreender a função da Mata Ciliar e suas características, que consiste na mata que se encontra ao longo dos cursos d'água (rios, córregos, lagos e lagoas). É caracterizada por ser bastante úmida, com abundante presença de samambaias e musgos. O nome "mata ciliar" vem do fato de serem tão importantes para a proteção de rios e lagos como são os cílios para nossos olhos, são como barreira que impede que a água do escoamento superficial escoe imediatamente para dentro do canal sendo liberada aos poucos para dentro do rio.Amparada pelo Código Florestal Federal como "área de preservação permanente" deve respeitar uma extensão específica de acordo com a largura do rio, lago, represa ou nascente(BRAGA et al., 2003).

De acordo com Nascimento (2001) há muitos benefícios oferecidos pela mata ciliar como:

- Proteção dos vegetais e animais, assim como os rios e nascentes e o solo com aumento da serapilheira, funciona como uma esponja que absorve a água evitando enxurradas

- Proporcionam abrigo a fauna, assim como alimento. 
- $\quad$ Favorece o fluxo gênico dentro das populações

- $\quad$ Aumenta a resistência das margens dos rios, pelas raízes das arvores, evitando assoreamento.

- Atua como filtro reduzindo a contaminação dos cursos d'água por detritos

- $\quad$ Oferece benefícios sociais como espaço de lazer e contato direto com a natureza

Em função disso neste ponto observa-se um arbusto característico de mata ciliar,o Sarandi (Colliguaja brasiliensis Klotzsch ex Baill.)encontrado nas margens do recursos hídricos, bem como em seu interior, mesmo quando estes possuem caráter temporário, permanecendo sem água em períodos de estiagem. (FERRARESE,2016). É presente no Brasil desde o RJ até o RS e no Uruguai, Paraguai e Argentina. Árvore que cresce apenas às margens dos rios, em áreas periodicamente alagadas. Possui importância por amenizar a erosão. Indicado para o reflorestamento das margens de rios. É comum uma parte das suas folhas cair no inverno (CEPPA,2008).

Ponto 5: Poço dos lambaris $\left(2^{\circ} 37^{\prime} 40.39^{\prime \prime} \mathrm{S} / 53^{\circ} 44^{\prime} 19.84^{\prime \prime} \mathrm{O}\right)$

Neste ponto o objetivo é compreender que a planície fluvial, conhecida como várzeas, são ambientes importantes para a manutenção do equilíbrio da dinâmica do rio, em tais condições a entrada e saída de sedimentos são equivalentes (BIGARELLA,2003) assim como do equilíbrio ecológico na RPPN Estadual MO’Ã. São elas que dissipam as forças erosivas do escoamento superficial de águas pluviais, funcionando como importantes controladores de enchentes e em época de chuva intensa forma pequenos córregos que deságuam no Arroio Manuel Alves, caracterizando canais entrelaçados, típicos de zonas montanhosas, com planície, formada a partir de depósitos coluvionares sob constante retrabalhamento pela complexa rede de canais de menor porte que são constantemente desativados/reativados de acordo com o período chuvoso (KORMANN et al., 2009). Após as chuvas os córregos secam e este pequeno poço se forma e nele se desenvolve um habitat de peixes de pequeno porte assim como anfíbios.Nesta parada o visitante pode desenvolver sua percepção sobre o meio, pois remete a um ambiente calmo de apreciação da vida de pequenas espécies, necessitando de atenção e silêncio.

Ponto 6: Fungo do ar puro (29³7'39.66"S/ 534ㄴ'22.07"O)

Neste ponto o visitante deve compreender a importância da preservação da mata ciliar para o rio, para a qualidade da água, e para nossa saúde,na qualidade do ar. Nos grandes centros urbanos os poluentes atmosféricos são os grandes causadores de problemas na saúde humana, principalmente respiratórios. A presença deste poluentes pode ser, muitas vezes, observada a partir da presença ou ausência de bioindicadores como os líquens. Para tanto deve-se observar as árvores e especificamente os seus troncos.No caso deste ponto percebe-se manchas rosas. Estas "manchas" são chamadas de líquens, que são 
seres vivos muito simples que constituem uma simbiose de um organismo formado por um fungo e uma alga; geralmente se proliferam nos substratos mais variados: sobre rochas, solo, casca das árvores e madeira. Podem ser de diversos tipos como Crostoso que é o caso deste ponto, onde o líquen fica preso no substrato, pode ser folioso tomando uma forma de folha, ou fruticoso tendo a forma de um arbusto. São seres pioneiros nas rochas nuas, dos solos de florestas queimadas e de escoadas vulcânicas.O ar atmosférico puro é fator fundamental à sobrevivência dos líquens, assim como bromélias, já que estes se alimentam da água presente do meio, fixando elementos neles presentes, especialmente o nitrogênio (GONÇALVEZ, 2007 apud VICENTE, 2012). Neste ponto podemos concluir que a qualidade do ar na RPPN Estadual MO’Ã é boa pela presença do líquen na árvore.

\section{REFERÊNCIAS}

BIGARELLA,J.J. Estrutra e origem das paisagens tropicais e subtropicais. Florianópolis: Ed. Da UFSC, 2003.

BRAGA, A.R.GRABHER,C;LAHÓZ,F.C.C;GOTARDI,K.R. Educação Ambiental para gestão de recursos hídricos:livro de orientação para o educador. São Paulo:Consórcio PCJ, 2003

BRASILPortaria n. 143, de 23 de dezembro de 2014b. Reconhece o Corredor Ecológico da Quarta Colônia, como instrumento de gestão territorial para promoção da conectividade entre o Parque Estadual da Quarta Colônia e demais alvos prioritários de conservação da biodiversidade identificados na região. Secretaria do Meio Ambiente.

Diário Oficial do Estado, Porto Alegre, RS. 16 dez. 2014. Disponível em: <http://www.biodiversidade.rs.gov.br/arquivos/14601366082014_Portaria_SEMA_n_143_Corredor_Ecologico_4_ _Colonia._nota_COM_MAPA.pdf>. Acesso em: 05 jan. 2016.

Lei n. 9.985 de 18 de julho de 2000, que regulamenta o art. 225, § $1^{\circ}$, inciso I, II, III e VII da Constituição Federal, instituiu o Sistema Nacional de Unidades de Conservação da Natureza e dá outras providências. Presidência da República - Casa Civil, Brasília, DF, 18 jul. 2000. Disponível em: <http://www.planalto.gov.br/ccivil_03/leis/19985.htm>. Acesso em: 20 abr. 2016.

Centro de Educação, Pesquisa e Preservação Ambiental. Florística. Descrição de Espécies Florestais: CEPPA, 2008. Disponível em http://www.unicruz.edu.br/floristica/descricao.php. Acesso em 13 de Nov. de 2016.

BRITTO,M.C; FERREIRA,C.C.M. Paisagem e as diferentes abordagens geográficas.Revista de Geografia PPGEO - v. 2, no 1 (2011). Disponível em http://www.ufjf.br/revistageografia/files/2011/12/Revista_Geografia_Dez2011Monique_Cristine_de_Britto1.pdf-51.pdf. Acesso em 09 de dez de 2016.

CAMPOS, J.B. et al.Unidades de Conservação: ações para a valorização da biodiversidade. Curitiba:Instituto Ambiental do Paraná, 2005.Disponível em http://observatorio.wwf.org.br/site_media/upload/gestao/documentos/IAP2005.pdf\#page=29. Acesso em 13 de Nov. de 2016.

CHAMI,L;DEON,M;SILVA,G.P. RPPN MO`Ã: Meios físico e biótipo. Disponível em: http://www.sema.rs.gov.br/upload/Estudo\%20T\%C3\%A9cnico.pdf. Acesso em 06 de Julho de 2016.

CHRISTOFOLETTI, A. Análise de Sistemas em Geografia. São Paulo: HUCITEC, 1979.

FERRARESE,M.D. Floristica de uma Reserva Particular do Patrimônio Natural em fragmento de Mata Atlântica(Itaara,RS,Brasil). Dissertação (de mestrado agrobiologia) 2016, 80p.

FLORA DIGITAL.Araucariaangustifolia (Bertol.) Kuntze. Disponível em http://www.ufrgs.br/fitoecologia/florars/open_sp.php?img=1179. Acesso em 14 de Nov. de 2016. 


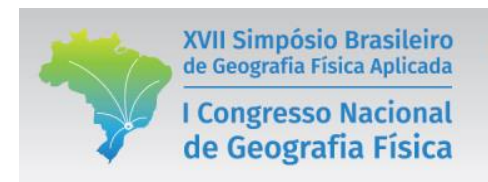
OS DESAFIOS DA GEOGRAFIA FÍSICA NA FRONTEIRA DO CONHECIMENTO
Instituto de Geociências - Unicamp
Campinas - SP
28 de Junho à 02 de Julho de 2017

IBGE. Instituto Brasileiro de Geografia e Estatística. Cidades. 2015. Disponível em: http://www.cidades.ibge.gov.br/xtras/perfil.php?lang=\&codmun=431053. Acesso em 06 de julho de 2016.

LIMA-GUIMARÃES, S.T. Trilhas Interpretativas e Vivências na Natureza:aspectos relacionados à percepção e interpretação da paisagem. Caderno de Geografia, v.20, n.33, 2010. Disponível em http://periodicos.pucminas.br/index.php/geografia/article/viewFile/1940/2117. Acesso em 18 de Nov. de 2016.

KORMANN, T. C.; ROBAINA, L. E. de S.; FOLETO, E. M. Mapeamento Geoambiental como subsídio à gestão de futura RPPN (Reserva Particular do Patrimônio Natural) em Itaara/RS. In: SIMPÓSIO BRASILEIRO DE GEOGRAFIA FÍSICA APLICADA, 13. 2009, Viçosa/MG. Anais... Viçosa: Universidade Federal de Viçosa, 2009. CD-ROM.

KORMANN, T. C.THOMAS,B.L;NASCIMENTO,D.B.FOLETO, E.M Contribuição Geográfica na Criação de uma Reserva Particular do Patrimonio Natural (RPPN) em Itaara- RS. Revista Geografar, Curitiba, v. 5, n. 2, p. 13-31, jul./dez. 2010. Disponível em: <http://revistas.ufpr.br/geografar/article/view/20138>. Acesso em 22 de jul. de 2016.

MAIEVES, H.A.et al.Uva-do-japão (Hoveniadulcis): Valor nutricionale aceitabilidade. Paraná, EMBRAPA, 2015. Disponível em http://ainfo.cnptia.embrapa.br/digital/bitstream/item/141814/1/Comunicado-Tecnico-361-2015-2903-2016.pdf. Acesso em 20 de Nov. de 2016.

MAGRO,T.C.FREIXÊDAS,V.M. Trilhas: como facilitar a seleção de pontos interpretativos. CIRCULAR TÉCNICA IPEF n. 186, Setembro de 1998.

NASCIMENTO, C.E.S. A importância das matas ciliares: rio São Francisco. Petrolina, PE: Embrapa Semi-Árido, 2001. Disponível em http://www.cpatsa.embrapa.br:8080/public_eletronica/downloads/SDC179.pdf. Acesso em 10 de dez. de 2016.

Secretaria do Meio Ambiente. Instituto Florestal. Manejo de Trilhas: Um Manual para Gestores. São Paulo: IF Série e Registros, n.35. 2008.

SILVA,D.M. A Caracterização da Interpretação Ambiental pelo conteúdo das mensagens: analise da atividade de um guia do Parque Estadual Mata dos Godoy(Londrina/PR. 2012,90f. Dissertação (mestrado em Ciências e Educação Matemática). Universidade Estadual de Londrina, 2012. Disponível em http://www.iap.pr.gov.br/arquivos/File/Pesquisa\%20em\%20UCs/Autorizacao_e_Projetos_2014/projeto_001.pdf.

Acesso em 20 de set. de 2016.

SOUZA, L.P.M. Plano de gestão turística do GeossitioGauritas-Caçapava do Sul/RS. 2014, 52f. Monografia (de graduação em Geografia). Universidade Federal de Santa Maria,2011.

TILDEN, F. Interpreting Our Heritage. The University of North Carolina Press, Chapel Hill. North Carolina, 1977.

VICENTE, R.R. A pesquisa no ensino de biologia: avaliação da qualidade do ar utilizando liquens como bioindicadores. 2012. Monografia (de especialização em Ensino de Ciências). Universidade Tecnológica Federal do Paraná - Campus Medianeira. 2012. 